\title{
Boal, leitor de Brecht: uma questão de método
}

Boal, Brecht's reader: a question of method

\section{Anderson Zanetti}

Anderson Zanetti

Doutor em Artes Cênicas pelo Instituto de Artes da Unesp de São Paulo

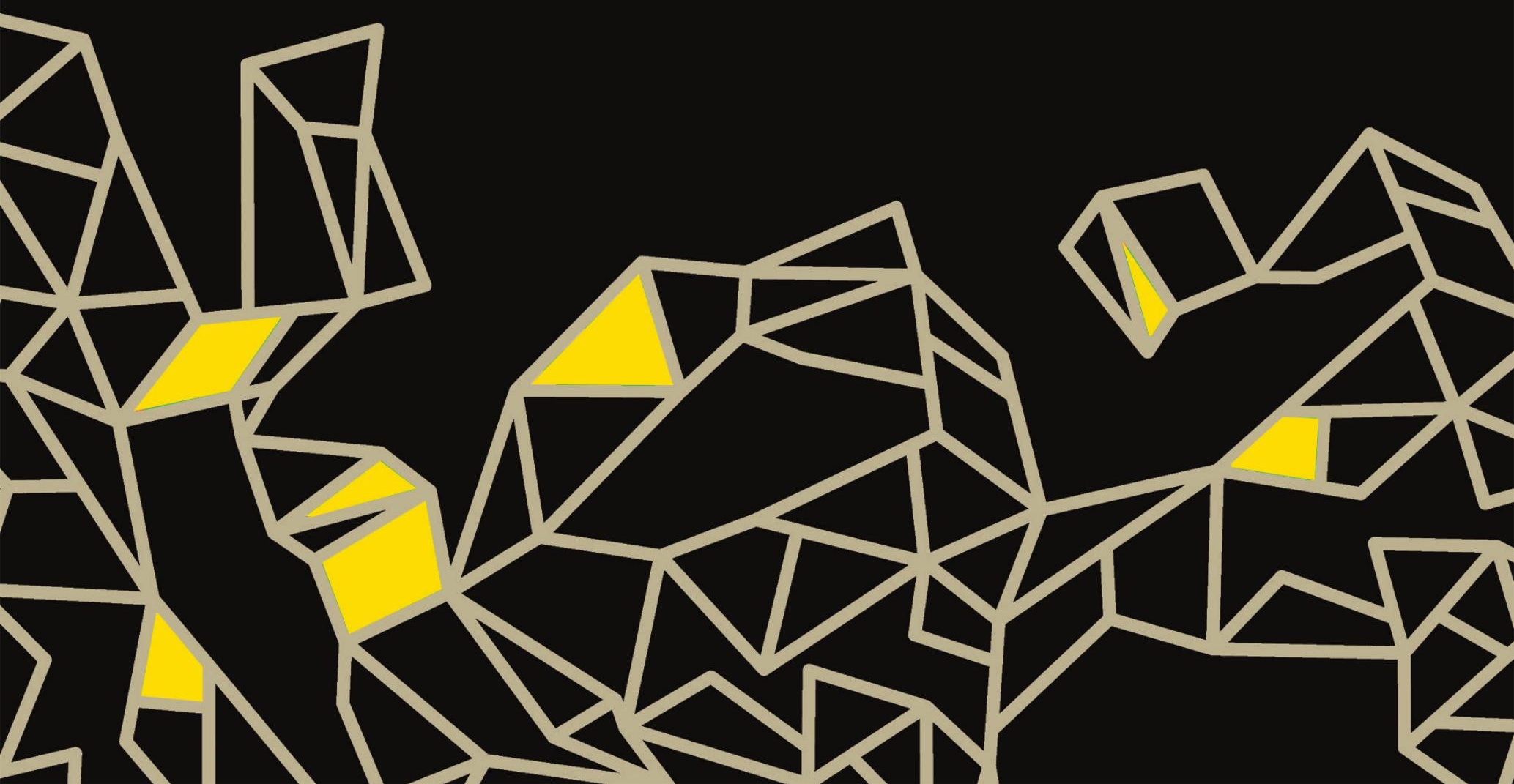




\section{Resumo}

Este artigo aborda o ensaio Hegel e Brecht: personagem-sujeito ou sujeito-personagem?, principal escrito de Augusto Boal acerca da poética de Bertolt Brecht. O objetivo é ressaltar que os limites da interpretação de Boal encontram-se na ausência de discussão acerca do papel do método da dialética materialista no trabalho de Brecht. Com isso, o raio de alcance da leitura de Boal não ultrapassaria o campo formal da crítica literária.

Palavras-chaves: Augusto Boal, Bertolt Brecht, Método, Dialética materialista.

\section{Abstract}

This paper approaches Hegel and Brecht: the character as subject or the character as object?, the most important essay written by Augusto Boal on Bertolt Brecht's poetics. The objective is to emphasize that Boal's limits of interpretation reside on the absence of discussion about the role of dialectical materialism in Brecht's work. Therefore, the range of Boal's reading would not overcome the formal scope of literary criticism.

Keywords: Augusto Boal, Bertolt Brecht, Method, Dialectical materialism.

O principal texto dedicado por Boal à poética brechtiana foi escrito em 1973, no seu exílio na Argentina, e faz parte da coletânea de artigos reunidos em Teatro do oprimido e outras poéticas políticas (BOAL, 2013). Com formato e linguagem de manual, o artigo Hegel e Brecht: personagem-sujeito ou sujeito-personagem? é uma tentativa consciente de traçar um panorama geral das diferenças elementares entre o que o teatrólogo denomina como a "poética idealista hegeliana" e a "poética marxista" de Brecht.

Dentre os principais méritos do escrito de Boal, vale a pena ressaltar o seu esforço em contribuir para a crítica teatral em um momento no qual pouco se estudava a teoria de Brecht no Brasil e na América Latina, bem como o destaque dado para a importância do pensamento de Marx na poética brechtiana (o que do ponto de vista político não é irrelevante, dado o contexto ditatorial latino-americano de aversão ao marxismo). Por outro lado, dois problemas que aparecem no ensaio de Boal merecem ser discutidos mais profundamente. 
O primeiro problema diz respeito à abordagem de confrontação de Brecht em relação a Hegel feita por Boal. Segundo o teatrólogo brasileiro, "Brecht se contrapõe a Hegel frontalmente, totalmente, globalmente" (BOAL, 2013, p. 105), e para sintetizar a questão afirma que "toda a Poética de Brecht é, basicamente, uma resposta e uma contraproposta à Poética idealista hegeliana” (BOAL, 2013, p. 98). Ou seja, Boal interpreta, de forma mecanicista, o teatro de Brecht como uma inversão da dialética idealista de Hegel para o materialismo dialético formulado por Marx. O segundo problema refere-se ao eixo discursivo usado por Boal, que é sustentado pelas suas definições de "personagem-sujeito", ao citar Hegel, e de "personagem-objeto", ao aludir a Brecht. Na perspectiva de Boal, essas duas definições estão ligadas ao conceito de "liberdade do personagem", ponto central de "confrontação" entre as duas poéticas. Sobre isso o teatrólogo brasileiro faz a seguinte consideração:

A confrontação central entre essas duas Poéticas (hegeliana e brechtiana) se dá no conceito de liberdade do personagem, como já veremos: para Hegel o personagem é inteiramente livre quer se trate da poesia lírica, épica ou dramática. Para Brecht (e para Marx), o personagem é objeto de forças sociais. (BOAL, 2013, p. 99, grifos do autor)

A leitura de Boal acerca das poéticas de Hegel e Brecht, na verdade, pertence predominantemente ao campo da crítica literária. Segundo o brasileiro, a poética hegeliana opera com a ideia de "gênero". Como o conceito de "épico" é um "gênero", a poética brechtiana não poderia ser chamada de "épica" porque ela não é um "gênero" nos termos da conceituação hegeliana. Conforme Boal, a poética de Brecht inclui "os gêneros lírico, épico e dramático" “(BOAL, 2013, p. 99). Em suma, o raciocínio de Boal é de que o teatro de Brecht não pode pertencer a um só "gênero" porque ele apresenta peças que pertencem aos três "gêneros". Nesse caso, o limite da perspectiva do brasileiro é tratar as obras de Brecht dentro de uma classificação literária idealista que vai de Platão a Hegel, quando na verdade o teatro do dramaturgo alemão não se resume a objetivos literários ${ }^{1}$.

Para não descartar completamente o uso dos termos lírico, dramático e épico do ponto de vista literário no teatro brechtiano, pode-se dizer que eles

1 Sobre a teoria dos gêneros, ver a parte I de ROSENFELD, 2006. 
aparecem na obra do alemão como traços estilísticos, tal como surge, por exemplo, a vanguarda expressionista nas suas primeiras peças. Efetivamente, como ressalta Anatol Rosenfeld (2006), Brecht passa a adotar o termo "teatro épico" no lugar de "drama épico" a partir de 1926 porque percebe que "o cunho narrativo da sua obra somente se completa no palco" (ROSENFELD, 2006, p. 147). Em outras palavras, é possível dizer que a realização dramatúrgica brechtiana é algo indissociável do palco, e isso a coloca em uma posição autônoma em relação à literatura.

As mudanças no modo de produção da arte aparecem no teatro como reflexo do uso de novos recursos técnicos e tecnológicos que, ao serem absorvidos por Brecht, ganham dimensões estéticas que a classificação da teoria dos gêneros aplicada ao universo literário não é capaz de comportar. Sobre algo parecido, Walter Benjamin (1994) chama atenção ao referir-se à consciência de Brecht em relação à condição da produção de arte no ascendente contexto da indústria cultural. Para o filósofo, enquanto muitos músicos, escritores e críticos acreditavam possuir os aparelhos de produção cultural, estes na verdade os controlavam e submetiam o produtor aos instrumentos de produção. Segundo Benjamin (1994), com essa consideração, "Brecht liquida a ilusão de que o teatro se funda na literatura" (p. 79).

No ensaio Que é teatro épico?, Walter Benjamin explica que o texto em Brecht não tem a função de preservar o teatro naquilo que ele é a partir de uma interpretação virtuosística, como ocorre com o teatro burguês. Ao contrário, o texto no teatro brechtiano serve de instrumento a favor da modificação do teatro. Conforme o filósofo, o texto é para Brecht uma ferramenta que serve de "roteiro de trabalho, no qual se registram as reformulações necessárias" (BENJAMIN, 1994, p. 79).

Segundo Benjamin, o teatro épico brechtiano é "gestual" sem impedir que existam elementos literários em suas obras. A questão é que, diferentemente do teatro burguês, que tem como fundamento o literário, o teatro épico de Brecht tem no "gesto" o seu material fundamental. Na visão de Benjamin, a vantagem disso é que, diversamente das palavras contidas em declarações mentirosas, os "gestos" humanos são menos falsificáveis, porque têm um começo determinável e um fim determinável. O uso do "gesto" no teatro épico de Brecht se torna potente porque nele é revelado aquilo que não é 
percebido habitualmente. É por esse motivo que Brecht interrompe as ações das personagens, pois a cada interrupção se extraem mais os "gestos" que as compõem; e o outro lado disso é fazer perceber as contradições existentes nas atitudes dos indivíduos.

Tudo assume o caráter de "gestos" (gestus) no teatro épico brechtiano, porque tudo mostra alguma coisa, tudo revela algo, tudo assume um papel narrativo: a música, a luz, o movimento do corpo e a ação interrompida pelo texto - tudo isso produz uma comunicação com o público que não se limita à palavra. Dessa forma, a palavra assume uma materialidade no palco que não é ilustração da ação, mas é a própria ação do ator que mostra o fluxo vivo no plano das ações sociais. Assim, no palco, tudo é atitude por parte dos atores que, ao invés de seguirem instruções para obter certos efeitos, devem assumir uma posição frente a teses expostas pelo diretor e a partir disso construir seus papéis, algo diverso do teatro burguês, no qual o trabalho de ator está voltado para a mímica que se estabelece a partir de papéis preestabelecidos.

Por conta dessas características, Benjamin (1994) ressalta que o teatro épico de Brecht não se reduz a reproduzir certas condições sociais, mas as descobre por meio da interrupção dos acontecimentos. Como destaca Gerd Bornheim (1992, p. 174), é com o interesse de proporcionar ao público um olhar de especialista que Brecht disseca as ações nos detalhes que as compõem para que, a cada instante, a cada som musical, a cada gesto dos atores, o público possa olhar para o acontecimento e analisar por diversos ângulos as suas causas. Em outros termos, é um processo de separação de elementos que se tornam independentes na composição do todo composto pela diversidade. $\mathrm{E}$ é por preservar cada elemento independente um do outro dentro de uma totalidade objetiva que o ponto de vista do especialista é o mais estimulado pela pedagogia teatral brechtiana, cuja dialética entre palco e público só acontece por meio do gestus. Nesse sentido, Walter Benjamin (1994, p. 88-89) ressalta:

O que se descobre na condição representada no palco, com a rapidez do relâmpago, como cópia de gesto humano, ações e palavras humanas, é um comportamento dialético imanente. A condição descoberta pelo teatro épico é a dialética em estado de repouso. Assim como para Hegel o fluxo do tempo não é a matriz da dialética, mas somente o meio em que ela se desdobra, podemos dizer que no teatro épico a matriz da dialética não é a sequência contraditória das palavras e ações, mas o próprio gesto. 
Aquilo que Benjamin chama de "um comportamento dialético imanente" é a "porta de entrada" para que o público seja ativado e a dialética brechtiana se complete. Diferentemente do drama burguês, no qual a dialética imanente da consciência volta sempre a si mesma, porque é idealista, a dialética imanente do teatro épico brechtiano só se realiza com a relação estabelecida fora de si, ou seja, na relação com o outro, que nesse caso é o público. Para Louis Althusser (1979), esse princípio da poética de Brecht pode ser encontrado nas teses de Marx acerca da dialética materialista, em contraposição à dialética idealista. Althusser chama atenção para o fato de que, segundo Marx, não é possível para uma consciência ideológica encontrar em si mesma uma saída de si a partir da sua própria dialética interna. É por isso que o próprio Hegel vê nas principais personagens da tragédia moderna a causa em si da ruína (o que se aplica também ao drama moderno).

Na visão hegeliana, é o excesso do desejo interior, o páthos, que faz que as personagens com "firmeza de caráter" sigam até o fim com seus planos e não tenham plena consciência de si no mundo e do conflito de seus interesses com o meio exterior. Segundo Hegel (2000), personagens como Macbeth, Otelo e Ricardo III possuem tal autonomia de caráter, pois o que lhes importa é a realização de suas paixões a qualquer custo, e o caminho para isso é submeter "caracteres mais fracos" às suas vontades, até que haja o encontro com outras subjetividades com "firmeza de caráter" e daí ocorra o conflito que levará a personagem protagonista à ruína final.

Nesse sentido, quando Boal afirma que, na poética hegeliana, "para que o personagem seja realmente livre é necessário que a sua ação não seja limitada a não ser pela vontade do outro personagem, igualmente livre" (BOAL, 2013, p. 101), o teatrólogo brasileiro não deixa de estar certo. Contudo, ao não abordar o método da dialética hegeliana a partir do seu projeto filosófico, que é o que pretende Hegel, Boal "pinça" somente um aspecto da verdadeira contraposição de Brecht em relação ao filósofo idealista.

O interesse de Marx e Brecht não está apenas no âmbito formal das contradições expostas pela dialética hegeliana, como no tratamento dado por Hegel à liberdade das personagens. Marx e Brecht estão interessados no método dialético, no seu poder de infiltração no real, ou seja, na explicação da 
realidade como um todo contraditório. Nos seus estudos acerca da dialética, Brecht (2002, p. 27) ressalta:

\begin{abstract}
A reprodução que Hegel faz da teoria aristotélica da arte na introdução à sua estética é de uma beleza extraordinária. $\mathrm{O}$ enunciado chave me parece ser: "Assim estabelece-se como objetivo final de seres humanos que vivem juntos, e do Estado, que todas as potencialidades humanas e todas as energias individuais devem desenvolver-se por todos os lados e em todas as direções a fim de alcançar expressão".
\end{abstract}

Brecht nota como o método hegeliano absorve o sistema aristotélico ao colocá-lo em um todo cujas partes, ao juntarem-se, caminham para um fim em comum: a realização da consciência como ser social. Todavia, como ressalta Marx, o problema de Hegel foi cair "na ilusão de conceber o real como resultado do pensamento que se sintetiza em si, se aprofunda em si, e se move por si mesmo" (MARX, 1978, p. 116-117).

Em Para a crítica da economia política, Marx (1978) ressalta que a produção da consciência pelo pensamento não parte dele mesmo como conceito abstrato na sua relação consigo, mas da relação com o mundo concreto e do modo como ele é produzido pelo próprio pensamento. É por não considerar essa condição sine qua non em determinado momento do pensamento que Hegel, na visão de Marx, cria um conceito de Estado pautado em um "misticismo" dialético.

Em outras palavras, se a dialética da consciência interna hegeliana caminha para uma projeção no Estado como forma de realização da própria consciência, a dialética da consciência em Marx e em Brecht busca sua realização no exterior como forma de mudança de si e do mundo concreto. É por isso que as personagens brechtianas não podem simplesmente receber o tratamento de personagem-objeto, como o dado por Boal. A personagem como objeto das forças sociais, em Brecht, faz parte de uma dialética a se completar no palco, porque o outro lado da consciência, que não se reconhece a si no mundo, a consciência alienada, é a tomada de consciência realizada pelo público. Ao mostrar uma parte (a personagem), Brecht está ao mesmo tempo mostrando o todo na relação com os indivíduos, e esse todo (a sociedade capitalista, ou o Estado como sua expressão) é aquele mesmo no qual está inserido o público. Como considera Althusser, "para produzir no espectador 
uma nova consciência, verdadeira e ativa, o mundo de Brecht deve necessariamente excluir de si toda pretensão de retomar-se e figurar exaustivamente sob a forma de uma consciência de si” (1979, p. 126).

É por conta disso, de uma pretensão que não se limita a buscar em si a sua realização dialética, que a poética de Brecht se põe em relação com a tradição de um tempo passado que continua vivo no presente, o que constitui a dimensão histórica daquilo que José Antonio Pasta Jr. (1986) considera como o trabalho brechtiano na construção de um projeto a perdurar no tempo. Segundo Pasta Jr., Brecht fez o trabalho permanente de resgatar, reunir, modificar e atualizar, na configuração total da sua poética, um sem número de linguagens artísticas que potencializaram o "salto dado no tempo" feito por sua obra que, ao se realizar, se coloca na posição de uma "classicidade contemporânea".

O trabalho de Brecht, buscando se realizar como um amplo projeto cultural, encontra nas tradições herdadas a diferenciação do "épico" no passado em relação ao "épico" do seu tempo. Ao pesquisar tanto a tradição ocidental, desde os antigos gregos aos românticos alemães, quanto a tradição oriental, da arte dramática chinesa, Brecht identifica que o "épico" em si, como elemento narrativo, seja pela dramaturgia ocidental ou pelo uso das máscaras orientais, sempre existiu. A diferença, porém, é que esses elementos narrativos do "épico" identificado por Brecht na tradição estavam a serviço da preservação do teatro tal como ele se colocava no mundo e, consequentemente, servia de instrumento de preservação de um determinado status quo social. É para diferenciar seu trabalho desse estado de coisas existentes no tempo passado e presente do fazer teatral que Brecht passa a usar o termo "teatro dialético" em vez de "teatro épico".

Por outro lado, o fundamento do "teatro dialético" de Brecht é ser "épico", mas um "épico" em relação com o método da dialética materialista, que não quer preservar o status quo social mantido pelo modo de produção capitalista. O trabalho de Brecht, portanto, é a realização do "épico" que se transforma e propõe a transformação do mundo material a partir das relações humanas. Isso significa considerar, diversamente do que afirma Boal (2013), que, por ser uma "poética marxista", a poética de Brecht é "épica" porque na tradição o elemento épico é aquele que busca a sua realização no mundo exterior, e é 
fundamentalmente essa característica não subjetivista que mais interessa ao dramaturgo alemão: o "épico" é incorporado pelo trabalho de Brecht para se concretizar como práxis revolucionária.

Para a realização desse projeto revolucionário, como salienta Pasta Jr. (1986), o trabalho brechtiano requer uma organização que não pode estar limitada ao personalismo. Para Brecht, a concretização de uma obra só pode se dar pela coletividade, e como o seu trabalho concentra e ao mesmo tempo expande sua obra, ela passa a não ser somente sua, mas do coletivo que com o dramaturgo organiza e realiza um projeto cultural.

Esse lado mais amplo da poética brechtiana, ou seja, o seu projeto de mundo, tem algo de semelhante com o encontrado por Augusto Boal ao longo da sua própria construção poética: um projeto de mundo no qual o oprimido construa coletivamente sua própria representatividade estética. Assim como em Brecht, em Boal o teatro concentra e propaga um projeto de ação cultural abrangente.

O teatro de Augusto Boal se aproxima em muitos aspectos ao teatro de Brecht. Porém, entre algumas das diferenças que existem entre as duas poéticas, a maior parte delas gira em torno da questão do método. Como proposta de trabalho coletivo e expansão social, Boal encontra em certos expedientes herdados da poética brechtiana um caminho a ser trilhado. Por outro lado, ao não adotar exatamente a dialética materialista como método, atendo-se a ter em Paulo Freire, principalmente na obra Pedagogia do oprimido (2000), uma referência ideológica e não necessariamente epistemológica, a poética de Boal permanece no tempo como um projeto revolucionário continuamente em busca de um método, ao passo que o teatro de Brecht perdura no tempo como uma poética que persiste em pôr em prática um método epistemológico como visão de mundo.

Visto o problema do ponto de vista histórico, o âmago da questão do método em Boal com relação a Brecht é um assunto em aberto no tempo e algo que o teatro brasileiro de vertente épica ainda procura resolver. Por outro lado, se na raiz do seu trabalho a poética de Boal permanece no tempo como a busca por um método epistemológico revolucionário, por outro ângulo o lado prático do seu projeto teatral se assemelha ao trabalho organizado por Brecht. 
Segundo José Antonio Pasta Jr. (1986), a organização do trabalho em Brecht, pela amplitude do seu alcance, é fruto de um projeto premeditado por parte do alemão. Tal premeditação posta em consonância com a visão de mundo da dialética materialista se torna um procedimento metodológico constituinte do trabalho de Brecht. É por ter consciência da grandeza do seu projeto que Brecht premedita inclusive a "glória da sua obra", organizando-a de tal maneira que só pode ser vista como fruto do trabalho coletivo. Para Pasta Jr., a magnitude da obra de Brecht se faz justamente porque, ao fugir de individualismos, o alemão prevê a grandeza de "só admitir sua consecução última como real e coletiva, consecução maior de que a obra quer ser emblema (modelo) e instrumento prático" (1986, p. 15).

Dadas as devidas proporções históricas e diferenças contextuais, ao longo da construção da sua poética, Augusto Boal encontra saídas semeIhantes a essas encontradas por Brecht, tanto no que diz respeito a sua obra como um todo quanto em relação à organização geral do Teatro do Oprimido (TO). Em todos os escritos teóricos que justificam sua prática com o TO, por exemplo, Boal deixa claro que o modo de organização e a concretização do seu trabalho acontecem coletivamente.

Nesse sentido, da mesma maneira como Jameson (1999, p. 129) considera que a autorreferencialidade em Brecht é coletiva e não individual, a autorreferencialidade também em Boal não aparece como certo aspecto do "modernismo" que coloca o artista em luta pela sobrevivência da individuação da sua obra diante da crise da arte. Antes disso, é o caráter coletivo da pedagogia teatral de Boal, tal como a de Brecht, que coloca a poética do teatrólogo brasileiro em relação com as tradições populares que a alimentam e a fazem fugir da autorreferência como um constante voltar-se a si. Semelhante à poética de Brecht, a poética de Boal só é autorreferência como procedimento de uma autorrevisão que se completa ao voltar-se para o mundo.

Tal como o projeto de Brecht, o trabalho de Boal visto pela sua amplitude de abordagens estéticas, inclusive no sentido de trabalhar também com diversas linguagens artísticas, é um trabalho que se propõe a perdurar no tempo na mesma medida em que se propõe a ser o tempo de um teatro gestado coletivamente com o objetivo de entrar para a história de maneira definitiva. Ao ressaltar a relação da obra de Brecht com o tempo, Pasta Jr. (1986, p. 22) 
considera que o projeto do alemão é a empresa de uma domada impaciente da história, porque quer concentrar o tempo e fazê-lo saltar: "este intento aparece como o de já surgir como um clássico, sem 'aguardar' o trabalho do tempo". Se o intento de Boal não é o de ser um clássico, conforme a tese de Pasta Jr. a respeito de Brecht, não é demais dizer que em termos de ação cultural o teatro do brasileiro se firma no tempo como um legado de teatro político tão ambicioso como o de Bertolt Brecht.

Em linhas gerais, é como se existisse, no interior da poética de Boal, uma força provocada pelo pensamento marxista que não se assume epistemologicamente como materialismo dialético, criando, assim, uma dialética própria de aceitação e não aceitação de Boal em relação a Marx e, consequentemente, a Brecht. Essa característica da construção poética de Boal traz consequências interessantes para a sua obra que, mesmo quando não se assume brechtiana, parece encontrar em elementos similares aos trabalhados por Brecht as saídas mais profícuas para seus experimentos estéticos.

\section{Referências bibliográficas}

ALTHUSSER, L. A favor de Marx. Rio de Janeiro: Zahar, 1979.

BENJAMIN, W. Magia e técnica, arte e política. São Paulo: Brasiliense, 1994.

BOAL, A. O teatro do oprimido e outras poéticas políticas. São Paulo: Cosac Naify, 2013.

BORNHEIM, G. Brecht - a estética do teatro. Rio de Janeiro: Graal, 1992.

BRECHT. B. Diário de trabalho. Rio de Janeiro: Rocco, 2002. v. 1.

FREIRE, P. Pedagogia do oprimido. Rio de Janeiro: Paz e Terra, 2000.

HEGEL, G. W. F. Cursos de estética. São Paulo: Edusp, 2000. v. 2.

JAMESON, F. O método Brecht. Petrópolis: Vozes, 1999.

MARX, K. Para a crítica da economia política. São Paulo: Abril Cultural, 1978. (Coleção Os pensadores).

PASTA JR., J. A. Trabalho de Brecht - breve introdução ao estudo de uma classicidade contemporânea. São Paulo: Ática, 1986.

ROSENFELD, A. Teatro épico. São Paulo: Perspectiva, 2006.

Recebido em 11/03/2017

Aprovado em 15/05/2018

Publicado em 29/06/2018 